\title{
Líquido da casca de caju (Anacardium occidentale L.) em grãos de trigo (Triticum aestivum) Tbio Toruk
}

\author{
Neyeli Cristine da Silva ${ }^{1}$, Bruna Gabriela Costa ${ }^{1}$, Ademir Mendes Cardoso Filho $^{2}$, Vildes Maria Scussel ${ }^{1}$
}

\begin{abstract}
Resumo
O trigo (Triticum aestivum L.) destaca-se por estar entre os grãos mais consumidos e de maior aporte nutricional do mundo. Todavia, é susceptível a sofrer com a contaminação por fungos que são potenciais produtores de micotoxinas, substancias ofensivas a humanos e animais. O Líquido da Casca da Castanha de Caju (Anacardium occidentale L.) (LCC) tem sido estudado como inibidor de inúmeros microrganismos devido à características químicas em sua composição que lhe conferem promissor potencial de inibição contra o desenvolvimento de fungos. A ação do LCC foi avaliada em grãos de trigo de armazenagem de um cultivar geneticamente modificado (Tbio Toruk). Para isso foram utilizadas 2 amostras de grãos de trigo de armazenagem,1 amostra foi submetida a tratamento com LCC e outra amostra isenta de tratamento foi usada para controle. Ambas passaram por posterior teste de semeadura direta dos grãos. Após o o período de incubação, foi calculada a porcentagem de crescimento fúngico. Quanto a qualidade das amostras, foram analisados parâmetros de umidade, atividade de água e ocorrência de micotoxinas. Os grãos sem o LCC apresentaram contaminação natural por fungos superior aos grãos impregnados com o liquid. Foi isolado dos grãos fungos do gênero Aspergillus spp. De acordo com os resultados obtidos, o LCC apresentou relevante opção como método de inibição do desenvolvimento fúngico.
\end{abstract}

Palavras-chave: trigo; micobiota; liquido da casca da castanha de caju.

\section{Introdução}

O trigo (Triticum aestivum L.) está entre os cereais mais consumidos no mundo devido ao seu valor nutricional. Por ser um grão rico em carboidratos merece atenção quanto à segurança alimentar, visto que, tal substrato é favorável ao desenvolvimento de fungos, que em determinadas condições ambientais podem vir a desenvolver micotoxinas, metabólitos secundários de certas cepas de fungos toxigênicos, (CARDOSO FILHO et al. 2016).

O controle e/ou descontaminação fúngica dos grãos de armazenagem é um grande desafio para indústria de alimentos que comumente adota o uso de agroquímicos (potencialmente ofensivos à saúde do consumidor, do produtor e meio ambiente) como método de proteção e/ou descontaminação (BRAIBANTE; ZAPPE, 2012; SAVI et al, 2019).

O Líquido da Casca da Castanha de Caju (Anarcadium occidentale L.) apesar de pouco valorizado no país, tem ganho interesse científico e industrial por seu baixo custo e composição fenólica que lhe confere vasta aplicabilidade biológica (MAZZETO et al. 2009). O uso do LCC pode resultar em benefícios ambientais, e contribuir para garantia da sustentabilidade do sistema de produção do caju, pois o aproveitamento integral das castanhas, e outros produtos reduzirá os impactos negativos da geração de resíduos de processos industriais (EMBRAPA, 2016).

Diante da importância econômica do trigo e da viabilidade e possíveis benefícios do aproveitamento do LCC no controle de contaminantes naturais de grãos armazenados, o presente trabalho objetiva avaliar a ação do LCC na micoflora de grãos de trigo de armazenagem do cultivar Tbio Toruk

\section{Material e Métodos}

Todas as análises foram realizadas no Laboratório de Micotoxinas e Contaminantes Alimentares do Departamento de Ciência e Tecnologia de Alimentos, do Centro de Ciências Agrárias da Universidade Federal de Santa Cantarina.

Os grãos de trigo de armazenagem $(4 \mathrm{~kg})$ do cultivar Tbio Toruk foram obtidos através da Companhia Integrada de Desenvolvimento Agrícola de Santa Catarina - CIDASC e passaram por análise de umidade (UR), atividade de água (Aw) e Multitoxinas. O Líquido da Casca da Castanha de Caju (LCC) f o i doado em grau técnico pela Usina Brasileira de Óleos e Castanhas (USIBRAS), Mossoró, RN.

Para realização das análises foram pesadas 2 amostras de grãos de trigo de armazenagem da variedade Tbio Toruk: $2 \mathrm{~kg}$ para grupo controle (GC) e $2 \mathrm{~kg}$ para grupo tratado (GT). Os grãos do GT foram tratados com LCC em concentração única de 40 $\mu \mathrm{L} / 20 \mathrm{~g}$, e a impregnação do LCC aos grãos de trigo foi realizada no interior de bequeres, com o auxílio de pipetador automático e submetidos à agitação manual durante dois minutos. Todos os testes foram realizados com repetição $(n=3)$.

Umidade e atividade de água: para verificar o conteúdo de umidade, $2 \mathrm{~g}$ de grãos de trigo foram submetidos a secagem em estufa $\left(105^{\circ} \mathrm{C} \pm 5^{\circ} \mathrm{C}\right)$ até peso constante pelo método gravimétrico. Para determinação da atividade de água, os grãos

\footnotetext{
${ }^{1}$ Laboratório de Micotoxinas e Contaminantes Alimentares (LABMICO), Departamento Ciência e Tecnologia dos alimentos, Centro de Ciências Agrárias, Universidade Federal de Santa Catarina (UFSC) Escola de Veterinária, Universidade Federal de Minas Gerais (UFMG). Rodovia Ademar Gonzaga n 1346 , Itacorubi, Florianopolis, Santa Catarina, CEP 88034-001, Brasil.

${ }^{2}$ Companhia Integrada de Desenvolvimento Agrícola de Santa Catarina (CIDASC). Rod. Admar Gonzaga, n 1588, Itacorubi, Florianopolis, Santa Catarina, Brasil. E-mail: neyeli_cristine@hotmail.com
} 
(2 g) foram submetidos a análise no equipamento Aqua- Lab 4TE. Foram realizadas 2 determinações em triplicata e de acordo com AOAC (2005).

Detecção de toxinas: seguindo o método de multi-toxinas para detecção de Aflatoxinas, Ocratoxina e Zearalenona (SOARES; RODRIGUES-AMAYA, 1989), primeiramente foi realizada a amostragem onde ( $500 \mathrm{~g}$ inteira) de amostra foi quarteada em Quarteador Jones para obtenção de amostras de menor massa, repetiu-se a operação até a obtenção de ( $50 \mathrm{~g}$ inteira), esta foi utilizada para juntamente à $270 \mathrm{ml}$ de metanol e $30 \mathrm{ml}$ de $\mathrm{KCl}$ $4 \%$ ef oi misturada em liquidificador por $5 \mathrm{~min}$. Em seguida realizou-se filtragem, e à $150 \mathrm{ml}$ do conteúdo filtrado, foi adicionado $150 \mathrm{ml}$ de sulfato de cobre e $50 \mathrm{ml}$ de terra diatomácea, que passaram por mistura, sedimentação e nova filtragem. Após a extração houve a limpeza do extrato, onde foram transferidos para um balão de $500 \mathrm{ml} 150 \mathrm{ml}$ do filtrado, $150 \mathrm{ml}$ de água destilada, e $4 \mathrm{ml}$ de clorofórmio, agitados vigorosamente por 2 min, para, após a separação ser realizada outra filtragem. Foi recolhido $5 \mathrm{ml}$ do extrato que passou por secagem no nitrogênio. Após secagem, preparouse a triagem em microcolunas, para por fim, ser realizada a quantificação em placas de CCD, com posterior confirmação. O limite de quantificação para as micotoxinas analisadas foi de $2 \mu \mathrm{g} / \mathrm{kg}$.

Micobiota das amostras de trigo: a técnica adotada é descrita por Berjak (1984) e denomina-se "semeadura direta" com algumas modificações. O ensaio foi realizado em triplicata, onde para cada cultivar do grupo controle (GC) e grupo tratado (GT com LCC) foram selecionados ao acaso 20 grãos de trigo e em seguida semeados diretamente nas placas de Petri contendo Ágar PDA em estufa $\left(25^{\circ} \mathrm{C}\right)$ por 7 dias com ausência de luz. Foi observado o número de grãos que apresentaram crescimento fungico, sendo os resultados expressos em porcentagem do total de grãos inoculados infectados por fungos, em seguida foi realizado o isolamento dos gêneros para confirmação da identificação destes, seguindo Samson et al. (2004).

\section{Resultados e Discussão}

Os resultados para os testes de umidade, Aw e porcentagem de crescimento fúngico estão apresentados na Tabela 1.

Tabela 1: Grãos de trigo (Triticum aestivum L.) do cultivar Tibio Toruk que apresentaram crescimento fúngico (\%) com e sem tratamento por líquido da casca da castanha de caju (Anacardium occidentale L.) (LCC)

\begin{tabular}{lcccc}
\hline \multirow{2}{*}{ Amostra } & \multicolumn{2}{c}{ Umidade } & \multicolumn{2}{c}{ Crescimento fúngico } \\
\cline { 2 - 5 } & $\mathrm{U}(\%)$ & $\mathrm{Aw}$ & $\mathrm{GC}(\%)$ & $\mathrm{GT}(\%)$ \\
\hline Toruk & 13,9 & 0,6467 & 45 & 5
\end{tabular}

U: teor de umidade; Aw: atividade de água; $\mathrm{T}\left({ }^{\circ} \mathrm{C}\right)$ : temperatura em graus celsius; GC(\%): grupo controle GT(\%): grupo tratado.

Teores de umidade superiores a $14 \%$ favorecemo desenvolvimento de fungos, com consequente produção de toxinas no período de armazenamento (MADARINO, 1994). Através da verificação da Aw no alimento, é possível relacionar a umidade presente com a habilidade microbiana de desenvolvimento no alimento, sendo a atividade de água mínima para o crescimento das principais espécies de fungos toxigenicos próxima a 0,7 a 0,8 (PITT; HOCKING, 2009). Apesar de a amostra estudada apresentar o valor de 0,6467 para Aw, valor este abaixo de 0,7, indicativo de menor probabilidade a crescimento fúngico, o teste de semeadura direta demonstra que houve crescimento fúngico (Figura 1.a). Este resultado pode ser devido às condições ambientais favoráveis encontradas no meio de cultura, uma vez que este apresenta Aw superior a 0,9, o que favorece o crescimento fúngico (MAGAN, 2006).

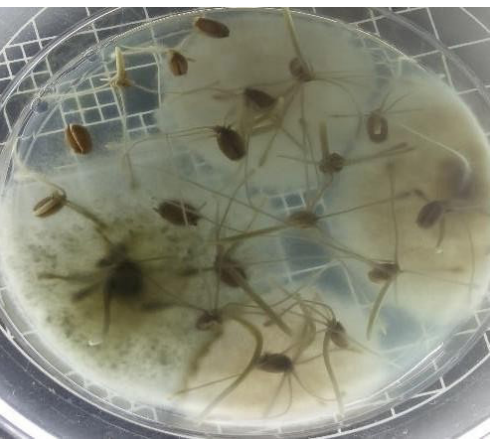

(A)

igura 1: Grãos de trigo (Triticum aestivum L.) do cultivar Tibio Toruk submetidos a teste emeadura direta.

Sem tratamento; (b) tratados com o líquido da casca de castanha de caju (Anacardium ccidentale L.)

Os grãos do GC (Figura 1.a) apresentaram contaminação fúngica naturalmente nos meios inoculados superior ao GT (Figura 1.b), isto é, aos impregnados com LCC. Isolou-se dos grãos sem tratamento (GC) o genêro Aspergillus spp (Figura 2). Segundo Scussel et al. (2018) o gênero Aspergillus está entre os principais fungos de armazenagem. Não houve detecção de produção de micotoxinas. Importante ressaltar que a produção de micotoxinas depende de alguns fatores como a linhagem do fungo, o tipo de substrato, temperatura, umidade, condições de colheita e/ou armazenamento, não estando necessariamente relacionada ao crescimento fungico (DRUSH;RAGAB, 2003).

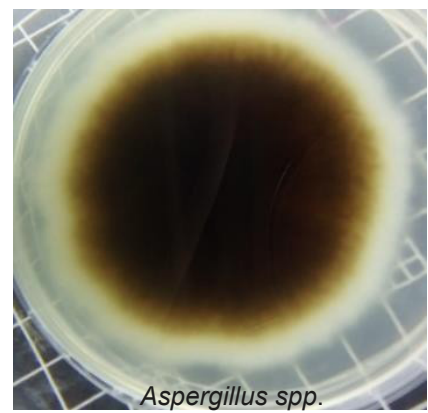

Figura 2: Colônia isolada (em ágar batata dextrose) de grãos de trigo (Triticum aestivum L.) do cultivar Tbio Toru (sem tratamento) submetidos a teste de semeadura direta.

O LCC (40 $\mu \mathrm{L} / 20 \mathrm{~g})$ mostrou-se um potencial antifúngico para o genêro Aspergillus spp.. Diversos estudos relatam resultados positivos do LCC como potencial antifúngico (SILVA et al.,2020). 
Matos e colaboradores (2017) relataram inibição de até 48\% do crescimento micelial do fungo Lasiodiplodia Theobromae pelas ações de diferentes concentrações do LCC. Bande, et al., (2018) investigaram a ação do LCC como antifúngico em fungos dos gêneros trichoderma e gliocladium. Os autores relataram que a utilização do biocida diminuiu o crescimento de ambos os microorganismos. Segundo Garcia et al., (2018) o L C C apresentou potencial antifúngico para Collethotrichum. gloeosporioides e Lasiodiploditheo bromae em frutos póscolheita. Outros compostos naturais são relatados como potenciais antifúngicos. Segundo Bonapaz et al. (2019) os óleos voláteis e extratos das plantas Foeniculum vulgare, Mentha piperita L. e Rosmarinus officinalis L. apresentaram potencial antifúngico, sendo o óleo para controle de fungo de armazenagem e o extrato para controle de fungo de lavoura.

\section{Referências}

AOAC, Association of Official Analytical Chemists. 2005. Official methods of analysis of AOAC International. Gaithersburg: AOAC, 2005.

BANDE, L.O.S.; GUSNAWATY, H.S.; TRISULPA, L. Botanical pesticides effect from shells of bean's cashew nut on biological agents of Trichoderma sp. and Gliocladium sp. IOP Conference Series: Earth and Environmental Science, 2018.

BERJAK, P.; DINI, M.; PAMMENTER, N.W. Possible mechanisms underlying dehydratation responses in recalcitrant and ortodox seeds: desiccation-associated subcellular changes in propagules of Avicennia marina. Seed Science and Technology, Zürich, v.12, p. 365-384, 1984.

BONAPAZ, L. S.; AFONSO, M. A.; DUTRA, M. S.; FRANCESCATO, L. N.; DIEL, V. B. N. Potencial fungitóxico de óleos voláteis e extratos vegetais no controle alternativo in vitro de fungos dos gêneros aspergillus e fusarium. Revista de ciências ambientais, v. 13, n. 3, 2019.

BRAIBANTE, M. E. F.; ZAPPE, J. A. A química dos agrotóxicos. Química nova na escola, v. 34, n. 1, p. 10-15, 2012.

CARDOSO FILHO, F. C.; CALDAS, M. L.; MURATORI, M. C. S. Fungos e aflatoxinas em cereais: Uma revisão. Revista de Ciência Veterinária e Saúde Pública, v. 2, n. 2, p.122-130, 2016.

DRUSH, S.; RAGAB, W. Micotoxinas em frutas, sucos de frutas e frutas secas. Journal of Food Protect, v.66, n.8, p.1514-1527, 2003.

EMBRAPA, Empresa Brasileira de Pesquisa Agropecuária. Valorização da casca da castanha de caju por meio do aproveitamento do LCC e do resíduo sólido. 2016.

GARCIA, N.Z.T.; BARBOSA, G.F.;MATIAS, R.; PEDRINHO, D.R.; BONO, J.A.M.;MARTINI, D. Antifungal potential of cashew nut shell liquid in the control of plant pathogens. Bio science Journal. v.34 n.1 p. 95-103. 2018.

MAGAN, N. Mycotoxin contamination of food in Europe: early detection and prevention strategies. Mycopathologia, v.162, n.3, p.245-253, 2006.

MATOS, D.M.A; ABREU, K.V.; OLIVEIRA, M.R.F. ; ROMÃO, A.L.E.; ABREU, K.L. ; ALVES, C.R.; SOARES, D.W.F. Atividade antifúngica e fitotoxicidade do liquido da casca da castanha de caju e seus constituintes frente ao fitopatógeno Lasiodsiplodia theobromae e Artemia salina. $57^{\circ}$ Congresso brasileiro de química. 2017.
De acordo com Savi (2019) a segurança para utilização de produtos naturais como potenciais fungicidas ainda não é bem estabelecida, sendo que concentrações excessivas não são recomendadas, podendo causar danos à saúde, por isso são necessárias avaliações quanto ao limite máximo de ingestão diária permitido.

\section{Conclusões}

A amostra de trigo estava naturalmente contaminada por fungos dos genêro Aspergillus spp.. Não houve detecção de produção de micotoxinas pelos fungos encontrados. O LCC demonstrou eficiência positiva como antifúngico frente ao gênero isolado Aspergillus ssp. . Todavia, se faz necessário avaliações quanto ao limite máximo de ingestão diária permetido para a aplicação do LCC, de modo a não causar danos à saude humana e animal.

MAZZETTO, S. E.; LOMONACO, D.; MELE, G. Cashew nut oil: opportunities and challenges in the context of sustainable industrial development. Quimica Nova, v. 32, n. 3, p. 732-741, 2009.

MAZZONCINI, M.; ANTICHI, D.; SILVESTRI, N.; CIANTELLI, G.; SGHERRI, C. Organically vs

conventionally grown winter wheat: Effects on grain yield, technological quality, and on phenolic composition and antioxidant properties of bran and refined flour. Food chemistry, 2015, 175, 445- 451.

PITT, J. I.; HOCKING, A. D. Fungi and Food Spoilage. 3 ed., New York: Springer Science 2009.

SAMSON, R. A., HOEKSTRA, E. S., FRISVAD, J. C. Introduction to Food - and Airborne Fungi. 7th ed.: Centraalbureau voor Schimmelcultures, Utrecht, The Netherlands, 2004.

SAVI, G. D. Estratégias de prevenção e de descontaminação de fungos toxigênicos e micotoxinas em alimentos. In: OLIVEIRA, L. A.; JESUS, M. A.; JACKISCH MATSUURA, A. B.; GASPAROTTO, L.; OLIVEIRA, J. G. S.; LIMA-NETO, R. G.; ROCHA, L. C. Conhecimento, conservação e uso de fungos, 2019, p.11-20.

SILVA, N. C.; COSTA, B. G. ; SILVA, B. A. ; SCUSSEL, V. M. . Cashew nut (Anacardium occidentale L.) shell liquid utilization as a strategy for the control of fungi in storage grains. IOSR Journal of agriculture and veterinary science, v. 13, p. 30-35, 2020.

SCUSSEL, V.M.; SAVI, G.D; KLUCZKOVVKI, A.M. Fungos e Micotoxinas associados aos grãos armazenados. In: LORINI, I.; MIIKE, L.H.; SCUSSEL, V.M; FARONI, L.R.D. Armazenagem de grãos. Jundiaí: Instituto BioGeneziz, 2018, p 735-758.

SOARES, L. M. V.; RODRIGUEZ-AMAYA, D. B. Survey of aflatoxins, ochratoxin $A$, zearalenone and sterigmatocystin in some Brazilian foods by using multi-toxin thin-layer chromatographic method. Journal of Association of Official Analytical Chemists International, Washington, v. 72, n. 1, p. 2226, 1989. 